\title{
Single CDTA-Based Current Mode All-Pass Filter and Its Applications
}

\author{
Neeta Pandey ${ }^{1}$ and Sajal K. Paul ${ }^{2}$ \\ ${ }^{1}$ Department of Electronics and Communications Engineering, Delhi Technological University, Delhi 110042, India \\ ${ }^{2}$ Department of Electronics Engineering, Indian School of Mines, Jharkhand 826004, India
}

Correspondence should be addressed to Neeta Pandey, n66pandey@rediffmail.com

Received 31 March 2011; Revised 20 July 2011; Accepted 4 August 2011

Academic Editor: Raj Senani

Copyright ( 2011 N. Pandey and S. K. Paul. This is an open access article distributed under the Creative Commons Attribution License, which permits unrestricted use, distribution, and reproduction in any medium, provided the original work is properly cited.

This paper presents a single current difference transconductance amplifier (CDTA) based all-pass current mode filter. The proposed configuration makes use of a grounded capacitor which makes it suitable for IC implementation. Its input impedance is low and output impedance is high, hence suitable for cascading. The circuit does not use any matching constraint. The nonideality analysis of the circuit is also given. Two applications, namely, a quadrature oscillator and a high $Q$ band pass filter are developed with the proposed circuit. The functionality of the circuit is verified with SPICE simulation using $0.35 \mu \mathrm{m}$ TSMC CMOS technology parameters.

\section{Introduction}

In filter applications pertaining to voice or audio frequency range, the magnitude characteristics play important role due to insensitivity of ear to change in phase whereas the phase characteristics dominate in video signal transmission. All pass filters are widely used for shifting the phase of the input signal while keeping the amplitude constant over the desired range of frequency. All-pass filters have also been used in the realization of dual element frequency controlled oscillator with certain benefits in harmonic rejection and quadrature property [1], multiphase oscillators [2], and high quality frequency selective filters [3].

The main intention of this paper is to present a current mode first order all-pass filter configuration based on CDTA [4]. A detailed study of available first order current mode allpass filters based on CDTA [5-11] reveals that they use single CDTA and external resistors $[5,6]$; two CDTAs and virtually grounded capacitor $[7-9,11]$; the structure in [10] rely on matching constraint. A current mode filter should exhibit low input and high output impedance for easy cascadability, and this feature is not present in structures $[5-9,11]$. The proposed current mode all-pass configuration uses a single CDTA called ZC-CDTA ( $Z$ copy CDTA) $[12,13]$ and a grounded capacitor. It presents low input impedance and high output impedance and uses no matching constraint. Two structures are presented in [10] which use a single ZCCDTA and a grounded capacitor as that of the proposed one. However, one of the structures in [10] uses more numbers of terminals than the proposed one whereas the other structure uses matching condition for filter realization. The circuit is also analyzed for nonidealities of CDTA. Two applications namely a quadrature oscillator and a high $Q$ band pass filter are developed using the proposed circuit. The functionality of all the circuits has been verified with SPICE simulations using $0.35 \mu \mathrm{m}$ TSMC CMOS technology parameters.

\section{Circuit Description}

The circuit symbol of ZC-CDTA is shown in Figure 1. The port relationships of the ZC-CDTA can be characterized by the following matrix: 


$$
\left[\begin{array}{c}
V_{p} \\
V_{n} \\
I_{z} \\
I_{\mathrm{zc}} \\
I_{x+} \\
I_{x-}
\end{array}\right]=\left[\begin{array}{cccccc}
0 & 0 & 0 & 0 & 0 & 0 \\
0 & 0 & 0 & 0 & 0 & 0 \\
1 & -1 & 0 & 0 & 0 & 0 \\
1 & -1 & 0 & 0 & 0 & 0 \\
0 & 0 & g_{m} & 0 & 0 & 0 \\
0 & 0 & -g_{m} & 0 & 0 & 0
\end{array}\right]\left[\begin{array}{c}
I_{p} \\
I_{n} \\
V_{z} \\
V_{\mathrm{zc}} \\
V_{x+} \\
V_{x-}
\end{array}\right],
$$

where $g_{m}$ is transconductance of the ZC-CDTA. The CMOSbased internal circuit of ZC-CDTA in CMOS [12] is depicted in Figure 2. The value of transconductance $\left(g_{m}\right)$ is expressed as

$$
g_{m}=\sqrt{2 \mu C_{o x}\left(\frac{W}{L}\right)_{21,23} I_{0}},
$$

which can be adjusted by bias current $I_{0}$ of ZC-CDTA.

The proposed first order all-pass filter based on ZCCDTA is shown in Figure 3. It uses a single ZC-CDTA and a grounded capacitor. The transfer function of the proposed circuit may be expressed as

$$
\frac{I_{\text {out }}}{I_{\text {in }}}=\frac{s C-g_{m}}{s C+g_{m}},
$$

and its corresponding phase response may be expressed as

$$
\varphi(\omega)=180^{\circ}-2 \arctan \left(\frac{\omega C}{g_{m}}\right) .
$$

It may be noted that there is no matching constraint for all filter realization and the pole frequency $\omega_{0}=g_{m} / C$ can be adjusted electronically by varying bias current $\left(I_{0}\right)$ of ZCCDTA.

\section{Nonideal Analysis}

The frequency performance of the filter circuit may deviate from the ideal one due to nonidealities. The nonidealities effect may be categorized in two groups: parasitics and transfer errors. The equivalent circuit of CDTA in presence of nonidealities may be represented as shown in Figure 4 [8]. The resistances $R_{p}$ and $R_{n}$ are parasitic impedances at $p$ and $n$ ports, respectively, whereas shunt output impedances $(R / / C)$ are present at ports $z, z c, x+$, and $x-$. The current transfer from $p$ and $n$ ports to $z$ port may differ from unity value and these tracking errors are represented by $\alpha_{p}$ and $\alpha_{n}$. The inaccuracy in transconductance transfer from $z$ to $X+$ and $X$ - ports is modeled by $\beta g_{m} V_{z}$. Considering the inaccuracies outlined above, the transfer function in (3) becomes

$$
\frac{I_{\text {out }}}{I_{\text {in }}}=\alpha_{n} \frac{s\left(C+C_{z}\right)+1 / R_{z}-\beta g_{m} R_{x} /\left(R_{x}+R_{p}\left(1+s C_{x} R_{x}\right)\right)}{s\left(C+C_{z}\right)+1 / R_{z}+\alpha_{p} \beta g_{m} R_{x} /\left(R_{x}+R_{p}\left(1+s C_{x} R_{x}\right)\right)} .
$$

For the CDTA circuit of Figure 2, the value of impedance at port $p$ is much smaller than port $x[12]$, hence (5) reduces to

$$
\frac{I_{\mathrm{out}}}{I_{\mathrm{in}}}=\alpha_{n} \frac{s\left(C+C_{z}\right)+1 / R_{z}-\beta g_{m}}{s\left(C+C_{z}\right)+1 / R_{z}+\alpha_{p} \beta g_{m}} .
$$

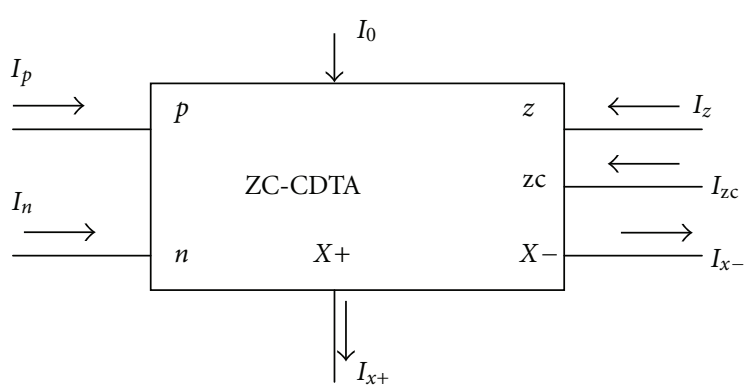

Figure 1: Circuit symbol of ZC-CDTA.

The value of $R_{z}$ is also very large so $1 / R_{z}$ can also be ignored. Thus (6) becomes

$$
\frac{I_{\text {out }}}{I_{\text {in }}}=\alpha_{n} \frac{s\left(C+C_{z}\right)-\beta g_{m}}{s\left(C+C_{z}\right)+\alpha_{p} \beta g_{m}} .
$$

The corresponding phase is obtained as

$$
\varphi(\omega)=180^{\circ}-\arctan \left(\frac{\omega\left(C+C_{z}\right)}{\beta g_{m}}\right)-\arctan \left(\frac{\left(\omega C+C_{z}\right)}{\beta \alpha_{p} g_{m}}\right) .
$$

It may be noted that the gain and pole frequency slightly deviates from their ideal values. In the proposed topology the parasitic capacitance $C_{z}$ may be accommodated in external capacitor $C$ and the pole frequency may be made closer to the designed value by adjusting the value of transconductance.

\section{Applications}

In this section, two applications of the proposed APF have been presented.

4.1. Quadrature Oscillator. The all-pass filter of Figure 3 may be used as quadrature oscillator when connected with an integrator in a closed loop. Figure 5 shows the desired connections. The analysis of the circuit of Figure 5 gives the following characteristic equation

$$
s^{2} C^{2}+s C\left(g_{m 1}-g_{m 2}\right)+g_{m 1} g_{m 2}=0 .
$$

The condition and frequency of oscillation are expressed as

$$
\begin{gathered}
\text { CO }: g_{m 1}=g_{m 2}, \text { that is, } I_{01}=I_{02}, \\
\text { if two ZC-CDTA are identical, } \\
\text { FO }: \omega_{0}=\frac{\sqrt{g_{m 1} g_{m 2}}}{C} .
\end{gathered}
$$

The relationship between two output currents $I_{\text {out1 }}$ and $I_{\text {out2 }}$ is obtained as

$$
I_{\text {out } 2}=\frac{g_{m 2}}{s C} I_{\text {out } 1} .
$$

Thus current outputs give quadrature relationship. It may also be noted from (10) and (11) that the frequency of the oscillations may be adjusted electronically with simultaneous adjustment of $I_{01}$ and $I_{02}$. 


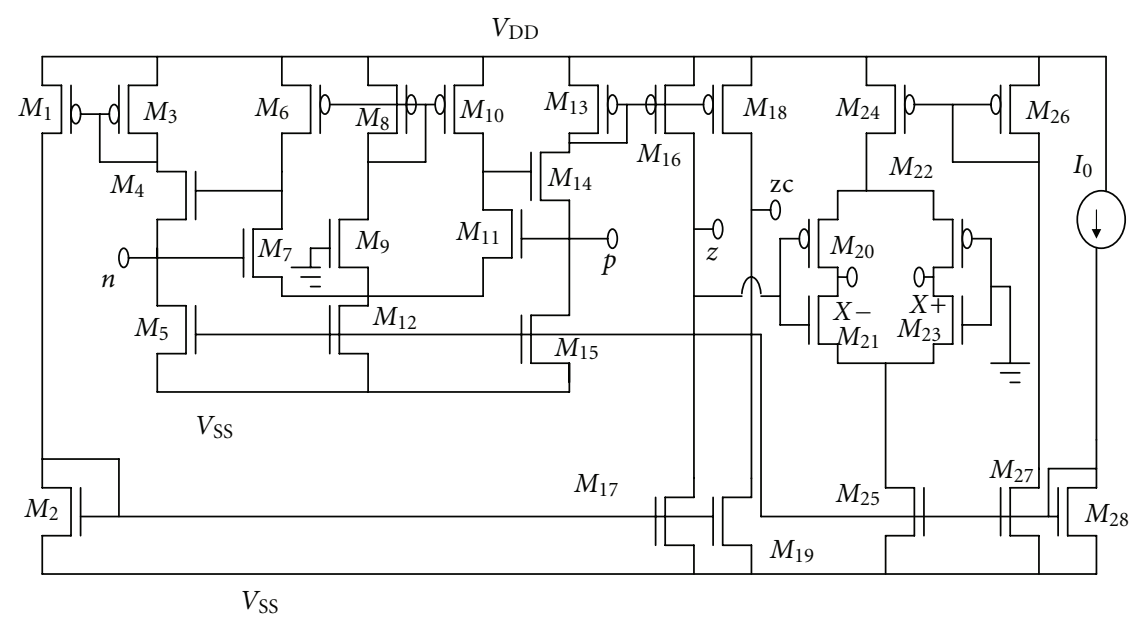

FIgURE 2: ZC-CDTA implementation.

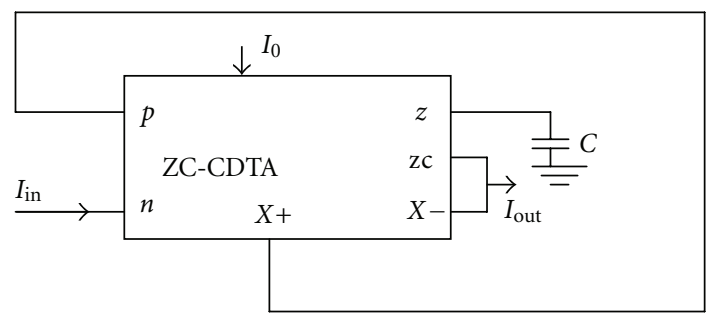

FigURE 3: Proposed current mode all-pass filter.

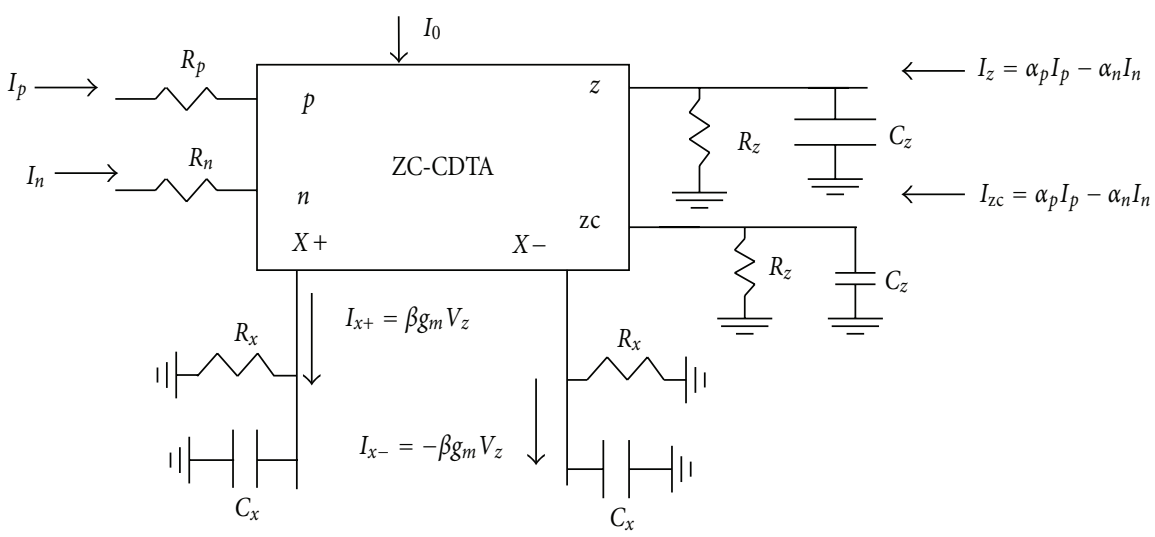

Figure 4: ZC-CDTA with nonidealities.

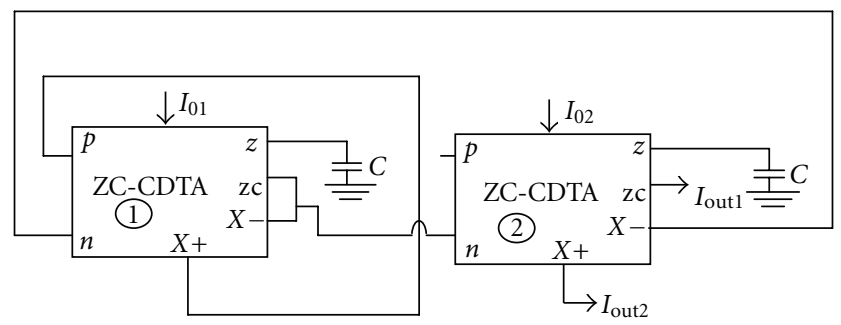

Figure 5: Proposed quadrature oscillator. 


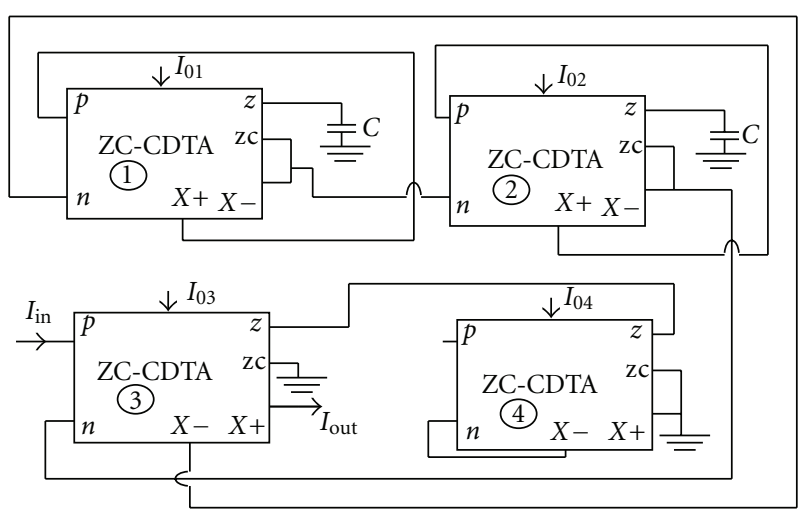

FIgure 6: Proposed band pass filter.

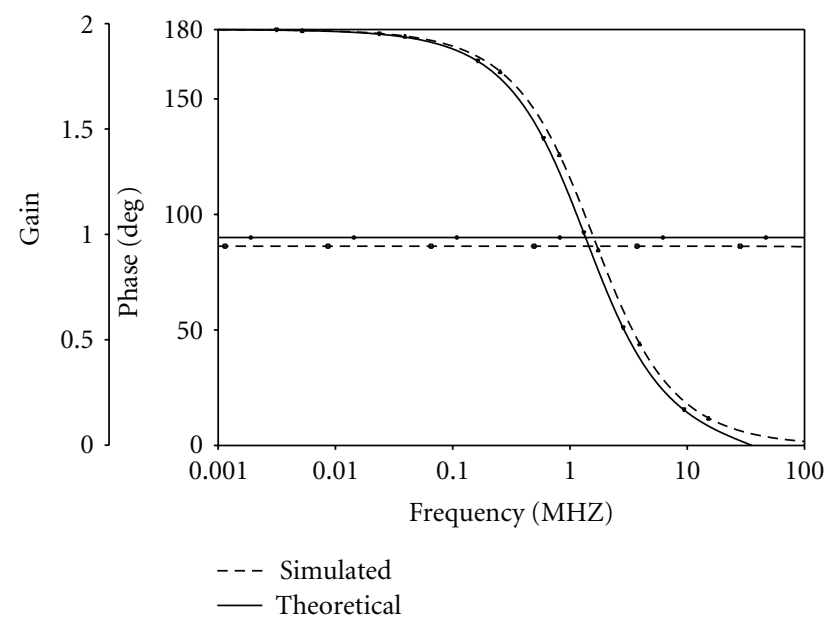

Figure 7: Magnitude and phase response of the proposed current mode all-pass filter.

4.2. Band Pass Filter. A high $Q$ band pass filter may be obtained with the proposed all-pass filter using the method proposed in [3]. The desired connections are shown in Figure 6. It consists of two all-pass filters in cascade (1st and 2nd CDTA) and a current amplifier (3rd and 4th CDTA) in feedback loop. The analysis of the circuit of Figure 6 gives the following transfer function:

$$
\frac{I_{\mathrm{out}}}{I_{\mathrm{in}}}=-\frac{K}{1+K} \frac{\left(s+\left(g_{m} / C\right)\right)^{2}}{s^{2}+2\left(g_{m} / C\right)((1-K) /(1+K))+\left(g_{m}^{2} / C^{2}\right)},
$$

where $g_{m}=g_{m 1}=g_{m 2}$, current gain $K=g_{m 3} / g_{m 4}$ is transconductance ratio of the $3 \mathrm{rd}$ and 4 th CDTAs. The filter parameters $\omega_{0}$ and $Q$ may be obtained as

$$
\omega_{0}=\frac{g_{m}}{C}, \quad Q=\frac{1}{2} \frac{1+K}{1-K} .
$$

It may be noted that the value of $Q$ may be adjusted by ratio of bias currents of the 3rd and 4th CDTA, and is temperature independent also. It may be noted that the transfer function of (13) has double zero at frequency $\omega_{0}$ and thus differ from ideal band pass transfer having a zero at

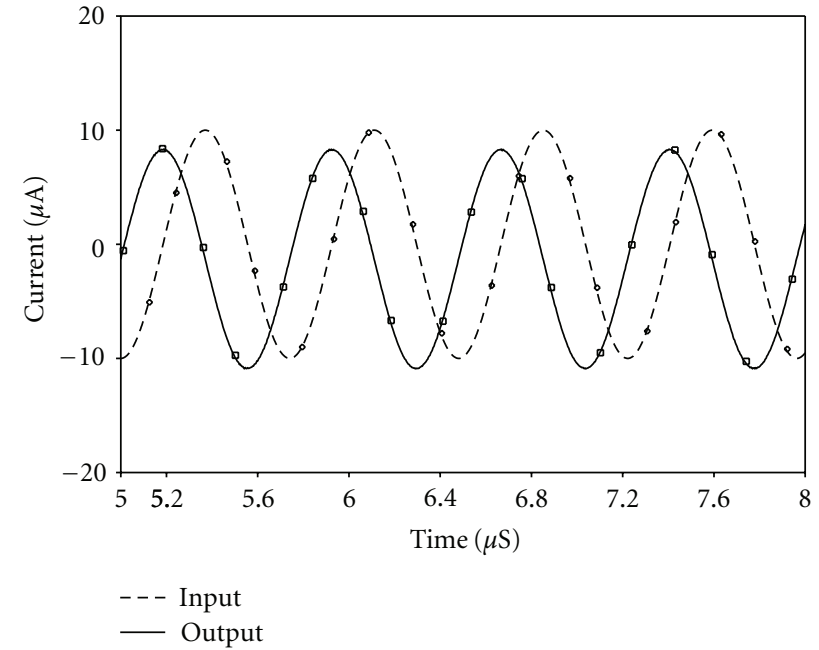

Figure 8: Transient response of the filter with sinusoidal input at $1.35 \mathrm{MHz}$.

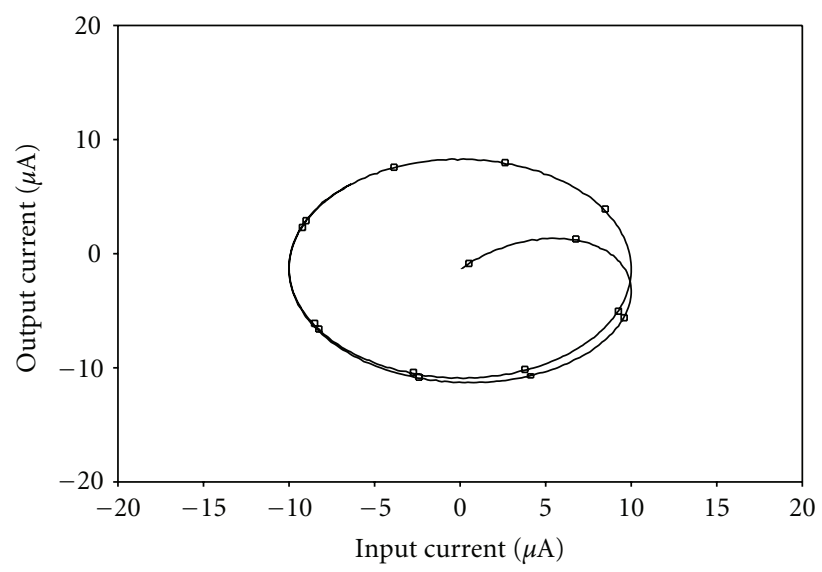

FIGURE 9: Relation between magnitudes of input and output.

origin. As a consequence, there will be deviation in the phase and magnitude responses but may be approximated as band pass response near center frequency [14].

\section{Simulation Results}

To validate the theoretical analysis, the circuit of Figure 3 is designed for a phase shift of $90^{\circ}$ at $f_{0}=1.35 \mathrm{MHz}$. The model parameters of TSMC $0.35 \mu \mathrm{m}$ CMOS process and supply voltages of $V_{\mathrm{DD}}=-V_{\mathrm{SS}}=1.8 \mathrm{~V}$ are used. The aspect ratios of various transistors are taken from [12] and the bias current of $40 \mu \mathrm{A}$ is used. The simulation results for magnitude and phase responses are shown in Figure 7 which show close agreement with the theoretical predictions. The transient response of the proposed all-pass filter, as shown in Figure 8, for a $1.35 \mathrm{MHz}$ sinusoidal signal clearly depicts a phase difference of $90^{\circ}$ between input and output. The relation between input and output magnitudes is shown in Figure 9. 


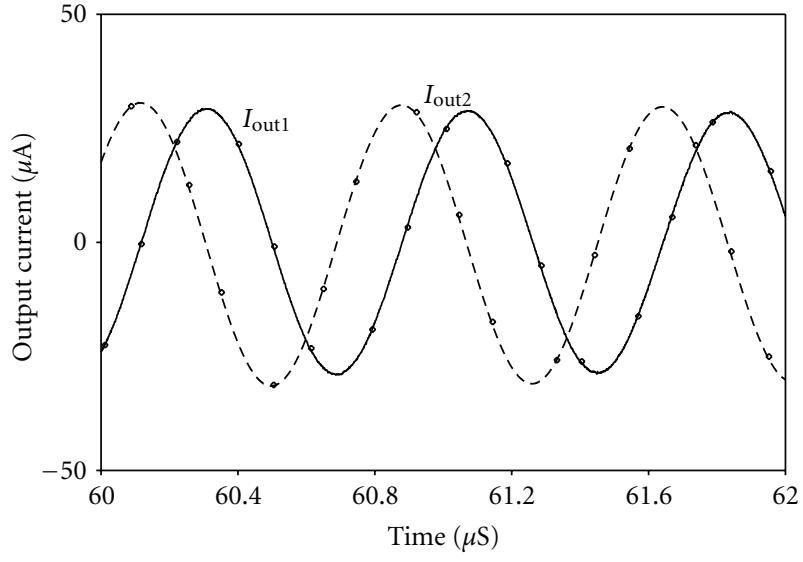

FIGURE 10: Quadrature current outputs of the proposed oscillator topology.

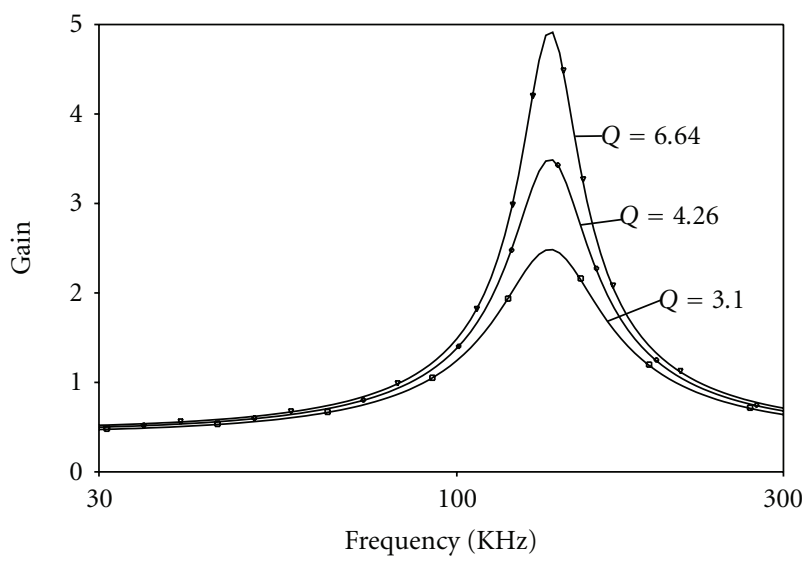

Figure 11: Magnitude plot of proposed band pass filter.

To demonstrate the functionality of quadrature oscillator, an oscillator is designed for $1.35 \mathrm{MHz}$ frequency. The various component values are $C=100 \mathrm{pF}$ and $I_{01}=$ $I_{02}=40 \mu \mathrm{A}$. The simulated results for current outputs of quadrature oscillator are shown in Figure 10.

The band pass filter is designed for $135 \mathrm{KHz}$ frequency with the $100 \mathrm{pF}$ capacitor and bias currents $I_{01}=I_{02}=I_{04}=$ $40 \mu \mathrm{A}$. The value of $Q$ is varied with bias current $\mathrm{I}_{03}$. The simulated results are shown in Figure 11.

\section{Conclusion}

A new CM first order all-pass filter configuration based on a single CDTA and one grounded capacitor has been presented in this paper. The topology is suitable for cascading as it possesses low input and high output impedances. It possesses attractive feature of electronic tunability of pole frequency and phase characteristics. Two applications are developed namely a quadrature oscillator and a high $Q$ band pass filter using the proposed all-pass filter. The functionality of proposed circuits is verified through SPICE simulations using $0.35 \mu \mathrm{m}$ TSMC CMOS technology parameters.

\section{References}

[1] J. V. Vosper and M. Heima, "Comparison of single- and dual-element frequency control in a CCII-based sinusoidal oscillator," Electronics Letters, vol. 32, no. 25, pp. 2293-2294, 1996.

[2] S. J. G. Gift, "Application of all-pass filters in the design of multiphase sinusoidal systems," Microelectronics Journal, vol. 31, no. 1, pp. 9-13, 2000.

[3] A. Toker, S. Ozoguz, O. Cicekoglu, and C. Acar, "Currentmode all-pass filters using current differencing buffered amplifier and a new high-Q bandpass filter configuration," IEEE Transactions on Circuits and Systems II, vol. 47, no. 9, pp. 949954, 2000.

[4] D. Biolek, "CDTA- Building block for current-mode analog signal processing," in Proceedings of the European conference on circuit theory and design (ECCTD '03), pp. 397-400, 2003.

[5] A. Uygur and H. Kuntman, "Low-voltage current differencing transconductance amplifier in a novel allpass configuration," in Proceedings of the IEEE Mediterranean Electrotechnical Conference (MELECON '06), pp. 23-26, May 2006.

[6] A. Ü. Keskin and D. Biolek, "Current mode quadrature oscillator using current differencing transconductance amplifiers (CDTA)," IEE Proceedings: Circuits, Devices and Systems, vol. 153, no. 3, pp. 214-218, 2006.

[7] W. Tanjaroen and W. Tangsrirat, "Resistorless current-mode first-order allpass filter using CDTAs," in Proceedings of the 5th International Conference on Electrical Engineering/Electronics, Computer, Telecommunications and Information Technology (ECTI-CON '08), pp. 721-724, May 2008.

[8] W. Tangsrirat, W. Tanjaroen, and T. Pukkalanun, "Currentmode multiphase sinusoidal oscillator using CDTA-based allpass sections," AEU-International Journal of Electronics and Communications, vol. 63, no. 7, pp. 616-622, 2009.

[9] N. Marungreang, W. Tanjaroen, T. Pukkalanun, and W. Tangsrirat, "Electronically tunable phase shifter using CDTAs," in Proceedings of the Annual Summit and Conference (APSIPA 09).

[10] A. Lahiri and A. Chowdhury, "A novel first-order currentmode all-pass filter using CDTA," Radioengineering, vol. 18, no. 3, pp. 300-305, 2009.

[11] W. Tangsrirat, T. Pukkalanun, and W. Surakampontorn, "Resistorless realization of current-mode first-order allpass filter using current differencing transconductance amplifiers," Microelectronics Journal, vol. 41, no. 2-3, pp. 178-183, 2010.

[12] D. Biolek, E. Hancioglu, and A. Ü. Keskin, "High-performance current differencing transconductance amplifier and its application in precision current-mode rectification," $A E U-$ International Journal of Electronics and Communications, vol. 62, no. 2, pp. 92-96, 2008.

[13] D. Biolek, R. Senani, V. Biolkova, and Z. Kolka, "Active elements for analog signal processing: classification, review, and new proposals," Radioengineering, vol. 17, no. 4, pp. 15-32, 2008.

[14] D. T. Comer, D. J. Comer, and J. R. Gonzalez, "A high-frequency integrable bandpass filter configuration," IEEE Transactions on Circuits and Systems II: Analog and Digital Signal Processing, vol. 44, no. 10, pp. 856-861, 1997. 

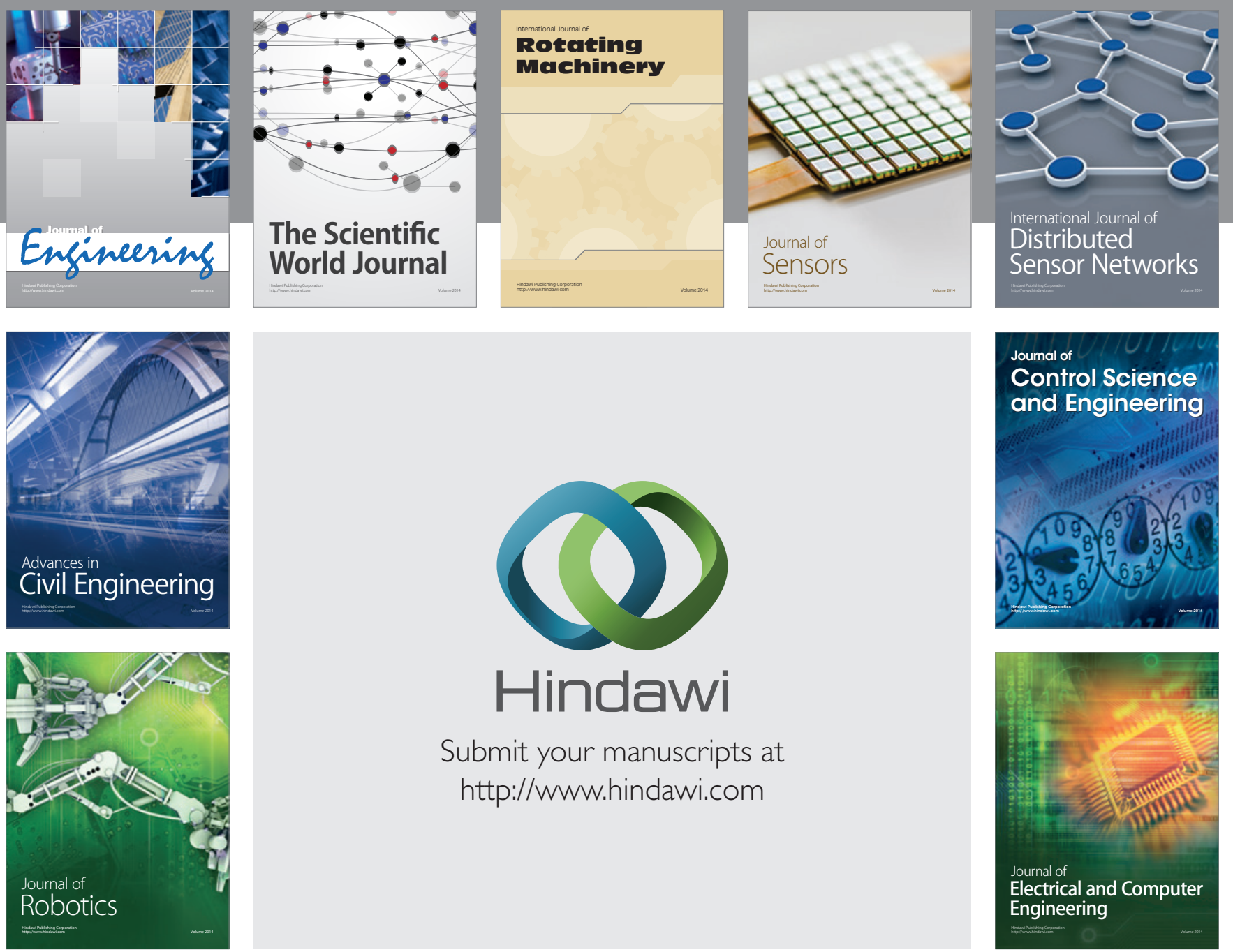

Submit your manuscripts at

http://www.hindawi.com
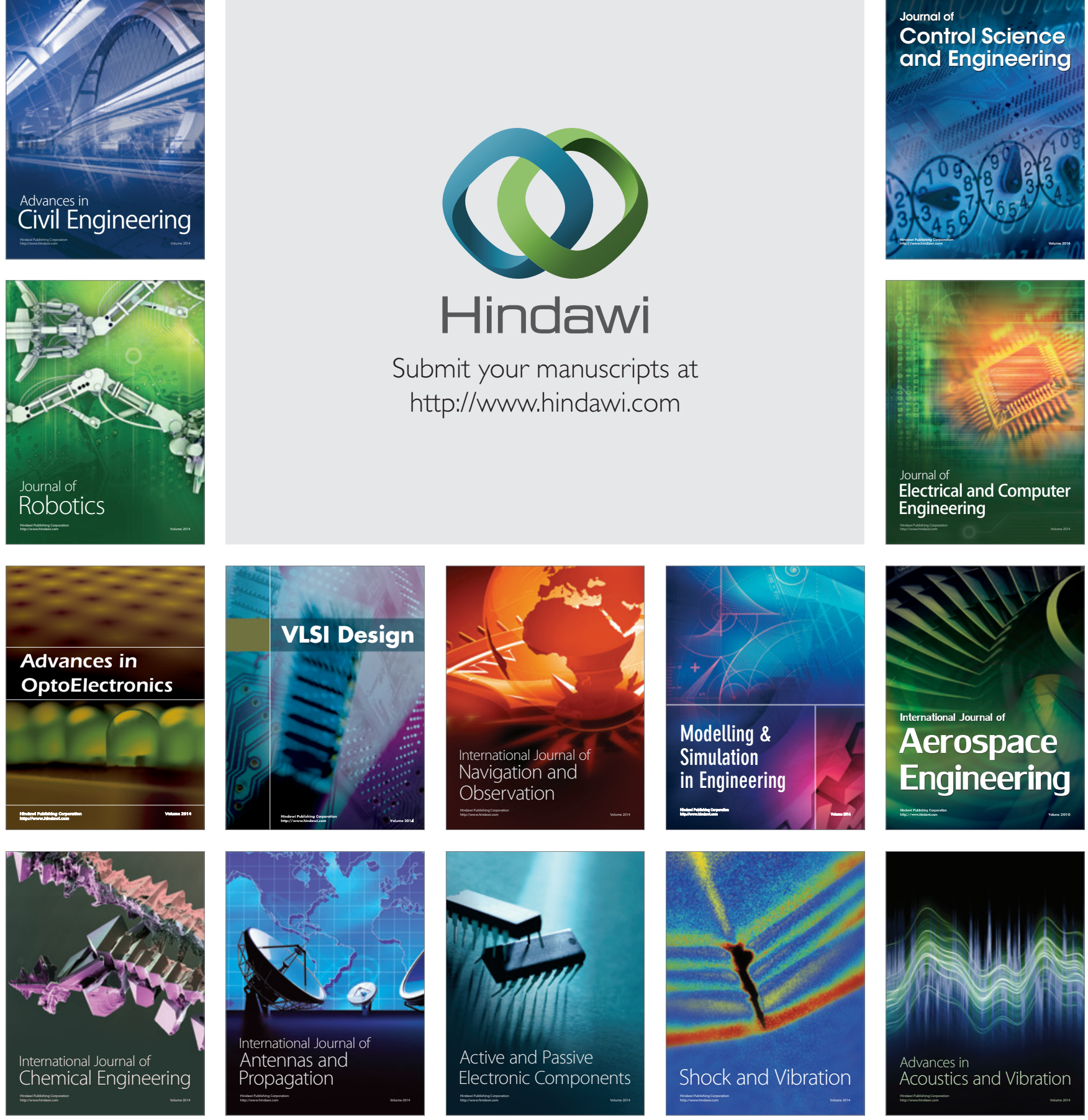